Published in final edited form as:

Hum Mov Sci. 2018 February ; 57: 59-68. doi:10.1016/j.humov.2017.11.006.

\title{
Changes of lumbar posture and tissue loading during static trunk bending
}

\author{
Faisal Alessa ${ }^{a, b, 1}$ and Xiaopeng Ning ${ }^{a,{ }^{*}}$ \\ aDepartment of Industrial and Management Systems Engineering, West Virginia University, \\ Morgantown, WV 26506, USA \\ bIndustrial Engineering Department, College of Engineering, King Saud University, Riyadh, Saudi \\ Arabia
}

\section{Abstract}

Static trunk bending is an occupational risk factor for lower back pain (LBP). When assessing relative short duration trunk bending tasks, existing studies mostly assumed unchanged spine biomechanical responses during task performance. The purpose of the current study was to assess the biomechanical changes of lumbar spine during the performance of relatively short duration, sustained trunk bending tasks. Fifteen participants performed 40-s static trunk bending tasks in two different trunk angles $\left(30^{\circ}\right.$ or $\left.60^{\circ}\right)$ with two different hand load levels $(0$ or $6.8 \mathrm{~kg})$. Results of the current study revealed significantly increased lumbar flexion and lumbar passive moment during the $40 \mathrm{~s}$ of trunk bending. Significantly reduced lumbar and abdominal muscle activities were also observed in most conditions. These findings suggest that, during the performance of short duration, static trunk bending tasks, a shift of loading from lumbar active tissues to passive tissues occurs naturally. This mechanism is beneficial in reducing the accumulation of lumbar muscle fatigue; however, lumbar passive tissue creep could be introduced due to prolonged or repetitive exposure.

\section{Keywords}

Static trunk bending; Lumbar flexion; Fatigue; Creep

\section{Introduction}

Lower back pain (LBP) remains one of the most prevalent health issues worldwide (Deyo, Mirza, \& Martin, 2006). It is estimated that approximately $80 \%$ of U.S. population will experience at least one episode of LBP in their lifetimes (Hellmann \& Imboden, 2009). Although the majority of people recover, approximately $20 \%$ of patients with acute LBP will experience chronic back problems (Weiner \& Nordin, 2010). Globally, occupational-related

\footnotetext{
"Corresponding author at: Industrial and Management Systems Engineering, P.O. Box 6070, West Virginia University, Morgantown, WV 26506, USA. fmalessa@mix.wvu.edu (F. Alessa), xiaopeng.ning@mail.wvu.edu (X. Ning).

1 The Ergonomics Lab, Industrial and Management Systems Engineering, West Virginia University, Morgantown, WV 26506, USA.

Disclosures

This research did not receive any specific grant from funding agencies in the public, commercial, or not-for-profit sectors and the authors declare no conflict of interests.
} 
LBP has been among the leading causes of lost work days. According to the World Health Organization 2010 Global Burden of Disease (GBD) study, LBP was ranked the 6th, (rising from the 11th in 1990), among top diseases and injuries that cause the largest number of Disability Adjusted Life-Years, which is a measure of the overall disease burden, expressed as the number of years lost caused by illness, disability or early death (Murray et al., 2012). In the United States, the economic burden associated with LBP is extremely large. Previous studies have estimated that the direct (e.g. medical) and indirect (e.g. lost work time, reduced productivity, etc.) cost related to LBP is around 100 billion dollars annually (Luo, Pietrobon, Sun, Liu, \& Hey, 2004; Katz, 2006).

The etiology of LBP is complex and multifactorial. Studies have found that LBP is associated with genetic (Junqueira et al., 2014), psychosocial (Gatchel, Polatin, \& Mayer, 1995), individual (Richard \& Edward, 1989), and biomechanical (Bernard, 1997; Marras et al., 1995) factors. Previously the association between the mechanical loading on spinal tissues and the risk of LBP has been demonstrated; it was found that excessive loading could cause fracture in the vertebral body (Brinckmann, Biggemann, \& Hilweg, 1988) and herniation in intervertebral discs (Adams, Freeman, Morrison, Nelson, \& Dolan, 2000), which further lead to spinal disorder and pain (Marras, Davis, Ferguson, Lucas, \& Gupta, 2001a). Although occasionally performed trunk flexion with moderate hand load is unlikely to cause immediate damage to the spinal structure, studies have found that prolonged and/or repetitive trunk flexion could generate micro damages to the spinal structure and eventually lead to LBP over a period of time (e.g. in months or years) (Brinckmann et al., 1988; Coenen, Kingma, Boot, Bongers, \& van Dieën, 2012; Coenen et al., 2013; Hoogendoorn et al., 2000; Norman et al., 1998). Thus, a clear understanding of the spinal tissue loadings during task performance is critical for the prevention of LBP.

The human lumbar spine mainly consists of two types of tissues: active tissues (e.g. the contractile component of muscles) and passive tissues (ligaments, fascia, discs, bone, and non-contractile component of muscles). It has been observed that during the performance of trunk bending, lumbar extensor muscle contraction will quickly diminish and cease action when reaching to the bottom range of the motion. Termed flexion relaxation phenomenon (Floyd \& Silver, 1951; Floyd \& Silver, 1955), this phenomenon indicates a complete transition of load from lumbar active tissues to passive tissues (Ning, Haddad, Jin, \& Mirka, 2011; Ning, Jin, \& Mirka, 2012), which is part of the load sharing synergy between these two types of lumbar tissues. Studies have shown that this load sharing synergy can be altered by a number of factors including ligament creep caused by prolonged trunk bending (Shin, D'Souza, \& Liu, 2009), the direction and speed of the trunk bending motion (Ning et al., 2011; Sarti, Lison, Monfort, \& Fuster, 2001), and lumbar muscle fatigue (Descarreaux, Lafond, Jeffrey-Gauthier, Centomo, \& Cantin, 2008).

Previous studies suggested that maintaining prolonged flexed trunk posture could elevate the risk of developing LBP due to increased spinal loading (Solomonow, Baratta, Banks, Freudenberger, \& Zhou, 2003; Bazrgari \& Shirazi-Adl, 2007) and muscle fatigue (Shin et al., 2009). Flexed trunk postures are commonly seen in several occupations such as construction (Boschman, van der Molen, Sluiter, \& Frings-Dresen, 2011), agriculture (Fathallah, 2010) and mining (Gallagher, 2008). In such postures, the interactions between 
lumbar active and passive tissues are mainly determined by lumbar postures (McGill, Hughson, \& Parks, 2000). As lumbar angle increases (i.e. flexed posture), lumbar passive tissues elongate and generate larger passive forces. Consequently, less lumbar active muscle forces are needed to counterbalance external moment (Arjmand, Plamondon, Shirazi-Adl, Lariviére, \& Parnianpour, 2011; Potvin, McGill, \& Norman, 1991). Previous efforts in studying prolonged static trunk bending postures have mostly focused on its contribution to lumbar passive tissue creep (McGill \& Brown, 1992) and the associated changes in lumbar biomechanics after prolonged flexion (Solomonow et al., 2003; Shin \& Mirka, 2007; Toosizadeh, Nussbaum, Bazrgari, \& Madigan, 2012). Other studies mostly assumed lumbar posture to be uniform and unchanged when holding static flexed trunk postures (Arjmand \& Shirazi-Adl, 2005; McGill et al., 2000; Kahrizi, Parnianpour, \& Firoozabadi, 2007). There is evidence that demonstrated the changes of lumbar biomechanics after prolonged static trunk bending (Hu \& Ning, 2015a, 2015b); however, the gradual changes of lumbar posture and its associated lumbar tissue load sharing profiles during the course of static trunk bending remains unclear.

Therefore, the aim of the current study was to investigate the changes of lumbar posture and the associated lumbar tissue loadings during the performance of relatively short duration, sustained trunk bending motions. Previous studies suggested that different lumbar postures may be used to adjust the level of lumbar extensor muscle exertions (Adams \& Dolan, 1995; McGill et al., 2000), such changes may be used to avoid or delay lumbar muscle fatigue during prolonged trunk flexion (Shin et al., 2009). Therefore, we hypothesized that when maintaining bended trunk postures, one may unconsciously increase lumbar flexion to shift external loading from lumbar active tissues to passive tissues in order to avoid muscle fatigue. Thus, we expect to observe increased lumbar flexion angle, reduced lumbar extensor muscle activity, and increased lumbar passive loading during the course of static trunk bending. We also hypothesized that these effects will increase at deeper trunk angles and with added external load.

\section{Materials and methods}

\subsection{Participants}

Fifteen male participants from the university student population (average body weight 76.2 $\pm 11.6 \mathrm{~kg}$, body height $173.7 \pm 8.9 \mathrm{~cm}$, age $24.9 \pm 4.0$ years) participated in the current study. All participants reported no current or history of LBP. Prior to the data collection, participants provided informed consent. The experimental design and procedure were approved by the Institutional Review Board of West Virginia University.

\subsection{Equipment}

Lumbar and trunk kinematics were collected using a magnetic field based motion tracking system (Motion Star, Ascension, Burlington, VT, USA). Three motion sensors were placed over the skin of C7, T12, and S1 vertebrae using double-sided tape (Ning et al., 2011). Muscular activities were sampled via eight bi-polar surface EMG electrodes (Bagnoli, Delsys, Boston, MA, USA), placed bilaterally over L3 and L4 paraspinals (L3P \& L4P) (4 $\mathrm{cm}$ and $2 \mathrm{~cm}$ away from the mid-line of the spinal column respectively), rectus abdominus 
(RA) $(1 \mathrm{~cm}$ above and $2 \mathrm{~cm}$ away from the umbilicus) and external oblique (EO) $(15 \mathrm{~cm}$ away from the umbilicus). Both EMG signals and kinematics data were sampled at $1024 \mathrm{~Hz}$. Finally, a custom-made reference frame was used for participants to reach and maintain designated trunk angles (Fig. 1).

\subsection{Independent and dependent variables}

The independent variables of the current study were trunk flexion angle (TA), hand load (LOAD), and duration of posture holding (DURATION). Two levels were considered for TA: $30^{\circ}$ and $60^{\circ}$ as they represent the mid-range of trunk flexion prior to the extreme load shifting from active to passive lumbar component which is reported to happen around $65^{\circ}$ of trunk flexion (Arjmand \& Shirazi-Adl, 2005). LOAD has two levels: 0 and $6.8 \mathrm{~kg}$ (i.e. 15 lbs). In each trial, participants were required to maintain a specific trunk angle with or without $6.8 \mathrm{~kg}$ of hand load for $40 \mathrm{~s}$. DURATION also has two levels and they were defined as the beginning $5 \mathrm{~s}$ and the ending $5 \mathrm{~s}$ of the task performance respectively. The load was made of disc weights and secured to a polyvinyl chloride (PVC) pipe, which was also used as handles. The combination of two levels of TA and two levels of LOAD generated four different conditions. In order to avoid the influence of lumbar muscle fatigue, participants performed only two repetitions of each condition, generating a total of 8 trials. Dependent variables of this study include: lumbar flexion angle (LA), lumbar passive moment (LPM) and normalized EMG (NEMG) from L3P, L4P, RA and EO.

\subsection{Experimental procedure}

Upon arrival, experiment procedures were explained to participants in detail and consent forms were then signed. Next, participants' basic anthropometric data (age, body weight, and height) were measured. Participants then performed a $\sim 10$ min training session to warmup back muscles and become familiar with the experiment protocol.

Prior to the data collection, surface EMG electrodes were secured to the designated locations. Then, participants performed two repetitions of isometric maximum trunk flexion/ extension exertions in a $20^{\circ}$ forward trunk flexion posture. An isokinetic dynamometer (Humac Norm, CSMi, MA, USA) was used to secure the pelvis and provide static resistance. The maximum EMG values obtained from maximum voluntary contraction (MVC) exertions were used later to normalize EMG activities. After completing MVC trials, motion sensors were fitted to the designated sites and participants then performed three full trunk flexion trials. These trials were performed to estimate LPM (see Section 2.5.4 for more details) (Ning \& Nussbaum, 2015). After that, the locations of the two required levels of trunk angle (i.e. $30^{\circ}$ and $60^{\circ}$ ) were determined for each participant using the motion sensors S1 and C7 (Fig. 2) and then marked on the apparatus. Then, participants were asked to perform sustained static trunk bending tasks. In each trial, participants were required to maintain an assigned trunk posture with or without holding a $6.8 \mathrm{~kg}$ hand load for $40 \mathrm{~s}$. The trunk angle was controlled using the apparatus showing in Fig. 1 in which participants were asked to keep their neck against the cross-rope, which can be adjusted to enable the two levels of trunk angle. The presentation of trails was randomized and 5 min of rest was provided between trials to avoid the accumulation of muscle fatigue. 
To evaluate lumbar muscle fatigue, two fatigue quantification tasks were performed before and immediately after the data collection in order to assess if significant lumbar muscle fatigue was developed. In the fatigue quantification trials, participants were asked to hold a 9 $\mathrm{kg}$ (i.e. $20 \mathrm{lbs}$ ) box in a $45^{\circ}$ trunk flexion posture for $6 \mathrm{~s}$ (see Section 2.5 .2 below) (Hu \& Ning, 2015a).

\subsection{Data processing}

2.5.1. EMG-EMG signals were first transferred into frequency domain and then filtered with a $10 \mathrm{~Hz}$ to $500 \mathrm{~Hz}$ band pass filter, and a notch filter of $60 \mathrm{~Hz}$ and its aliases. The EMG data were then transferred back to the time domain, fully rectified and smoothed with dual fourth-order Butterworth low-pass filter with a cutoff frequency set at $2 \mathrm{~Hz}$. EMG profile from each muscle was then normalized to the corresponding maximum EMG collected during MVCs. Muscle fatigue was characterized by the reduction of EMG median frequency (De Luca, 1997).

2.5.2. Muscle fatigue evaluation-In the current experimental design, one of the goals was to eliminate the influence of lumbar muscle fatigue on the synergy of lumbar active muscles and passive tissues as much as possible. Thus, participants who showed a decrease of more than $8 \%$ in EMG median frequency from the fatigue measurements trials were excluded from the dataset. This threshold is conservative relative to findings from previous studies, in which, approximately $12 \%$ decrease in EMG median frequency was observed with the onset of significant lumbar muscle fatigue (Hu \& Ning, 2015a, 2015b). A paired $t$ test was also performed to evaluate if significant decrease of EMG median frequency occurred after the testing protocol.

2.5.3. Kinematics-The three-dimensional coordinates of the three motion sensors were used to calculate trunk and lumbar flexion angles. Trunk flexion angle was defined as the angle between the vertical line and the line between the $\mathrm{C} 7$ and the $\mathrm{S} 1$ motion sensors, natural upright posture gives a $\sim 0$ value. Lumbar flexion angle was defined as the difference between the pitch angles of the T12 and S1 motion sensors in the sagittal plane (Fig. 2) (Ning et al., 2011).

2.5.4. Lumbar passive moment (LPM)-The estimation of LPM was performed following a previously established approach (Ning \& Nussbaum, 2015). The magnitude of lumbar passive moment is determined by the deformation of these tissues. As lumbar spine flexes, the lumbar posterior passive tissues elongate and result in higher stress. Therefore, in the current study the magnitude of lumbar passive moment was calculated as a function of lumbar flexion angle during trunk flexion motion.

For each full trunk flexion trial, the lumbar passive moment was estimated as the difference between the external moment and the internal active moment. The external moment at the L5/S1 joint during the full trunk flexion was calculated as a function of the upper body mass, center of mass, trunk flexion angle, and instantaneous acceleration (Mirka, Baker, Harrison, \& Kelaher, 1998; Ning \& Nussbaum, 2015). The internal active moment was estimated using a previously published EMG-assisted model (Marras \& Granata, 1997; Ning

Hum Mov Sci. Author manuscript; available in PMC 2019 February 01. 
et al., 2012). This biomechanical model uses normalized EMG signals from L3 and L4 paraspinals, RA, and EO to estimate the instantaneous muscle forces and moments about the L5/S1 joint. After that, the profiles of the lumbar passive moments during trunk flexion trials were obtained and modeled using Eq. (1) (Ning \& Nussbaum, 2015). In this equation $L P M$ is the lumbar passive moment; $a$ is the lumbar angle; $c$ is a participant-specific constant that represents the initial lumbar angle in the upright standing posture; and $\sigma_{\mathrm{i}}$ and $\beta_{\mathrm{i}}$ are model parameters for subset $i$ (i.e. before and after active region boundary (ARB) point). ARB is the point at which the active moment starts to decrease drastically (Ning et al., 2012). A custom computer program was used to estimate the parameters of the equation for each participant using empirical data from full trunk flexion trials. Finally, LPM at the beginning and the ending of the static trunk bending tasks were obtained using Eq. (1).

$$
\operatorname{LPM}(a)=\sigma_{i} \times\left(\frac{e^{\beta_{i} \times(a-c)}-1}{e^{\beta_{i}}-1}\right)
$$

\subsection{Statistical analysis}

The statistical analysis was conducted in two steps. First, paired $t$-test was performed to assess the effect of DURATION on all dependent variables. Thus, dependent variables obtained in the beginning of each trial were compared to the ending of the same trial. Second, two-way ANOVA was performed to analyze the influence of TA and LOAD on the changes of dependent variables from the beginning to the end of static trunk bending tasks. All statistical analyses were performed using Minitab 17 statistical analysis software (Minitab Inc., PA, USA) and criteria p-value of .05 was used.

\section{Results}

\subsection{The control of TA and lumbar muscle fatigue}

According to the kinematics data, trunk angles were successfully controlled for both $30^{\circ}$ and $60^{\circ}$ conditions. The actual trunk angle remained unchanged during the task performance of the $40 \mathrm{~s}$ of posture holding. The mean and standard deviation of trunk angles at the beginning and the ending of $30^{\circ}$ and $60^{\circ}$ conditions were $30.6^{\circ}\left(1.2^{\circ}\right), 30.5^{\circ}\left(1.3^{\circ}\right)$ (p-value $=.33)$ and $60.1^{\circ}\left(0.9^{\circ}\right), 60.1^{\circ}\left(1.2^{\circ}\right)(\mathrm{p}$-value $=.63)$ respectively. Thus, the external moments were relatively constant during the static posture holding trials. In addition, none of the 15 participants was excluded by the fatigue exclusion criterion; data from the fatigue measurement tasks showed that no significant reduction of lumbar muscle EMG median frequency was observed, ( $p$-values are .78 and .79 for $30^{\circ}$ and $60^{\circ}$ conditions respectively), which indicate that no significant muscle fatigue was developed among lumbar muscles during the experiment. Finally, the averages lumbar flexion angle at the $60^{\circ}$ posture for all participants were well below their maximum lumbar flexion angles (Table 1). 


\subsection{The effects of DURATION}

Results of statistical analyses showed that DURATION significantly influenced the majority of dependent variables under different TA and LOAD conditions. More specifically, when holding a static trunk flexion posture for $40 \mathrm{~s}$ participants demonstrated significantly increased lumbar angle in 3 out of 4 conditions (except the $30^{\circ} \mathrm{TA}$ and $6.8 \mathrm{~kg}$ LOAD condition) (Fig. 3), and significantly higher LPM was observed in most conditions (Fig. 4). The current result also showed significantly reduced muscle activities among lumbar extensor muscles (i.e. L3 and L4 paraspinals) in almost all conditions (Fig. 5), a reduction of abdominal muscle activity was also observed but it was only significant in the $30^{\circ}$ trunk flexion posture (Fig. 6).

\subsection{The effects of TA and LOAD}

The influence of TA and LOAD on the changes of dependent variables (calculated as the difference in each dependent variable between the beginning and the ending of the task performance) was also assessed. Results showed that TA significantly affected the amount of change on all dependent variables except for the L3 paraspinals. The effect of LOAD and the interaction effect between TA and LOAD were not significant (Table 2). The average and standard deviation of the amounts of changes of all dependent variables during static trunk bending (corresponding to different trunk angles) are listed in Table 3.

\section{Discussion}

The goal of current study was to investigate the changes in lumbar biomechanics during the performance of short duration, static trunk bending motions. During the experiment, participants maintained a $30^{\circ}$ or $60^{\circ}$ of flexed trunk posture with or without a hand load (i.e. $6.8 \mathrm{~kg}$ ) for $40 \mathrm{~s}$. Results showed significantly increased lumbar flexion angle, reduced trunk muscle activities and elevated LPM. To further assess the development of muscle fatigue during the data collection, a fatigue comparison was applied between the outcomes of the first and second repetitions within each condition. The MANOVA analyzed the influence of Trunk Angle, LOAD, and trial sequence (i.e. 1st or 2nd) on the amount of changes of dependent variables at the end of the static trunk bending tasks. Results of MANOVA showed that the influence of trial sequence was not significant $(\mathrm{p}$-value $=.7)$. This result serves as an additional indication that muscle fatigue was controlled throughout the data collection.

In a flexed trunk posture, the external moment at the L5/S1 joint is counterbalanced by both lumbar active and passive tissues (Arjmand \& Shirazi-Adl, 2005). With the increase of lumbar flexion angle, lumbar passive tissues elongate and therefore generate larger elastic forces. Thus, less muscle contraction is needed to counterbalance the external moment. In the current study, the observed reduction of lumbar muscle NEMG confirmed this mechanism. These findings also demonstrated the important role of lumbar posture in determining lumbar tissue loadings; which concurs with the previous literature (Arjmand \& Shirazi-Adl, 2005; McGill, 1997; Ning \& Nussbaum, 2015; Potvin et al., 1991). 
One possible explanation for the load shifting from lumbar active to passive tissues is that, there may be an internal motor strategy to help delay the accumulation of lumbar muscle fatigue by shifting more loading to lumbar passive tissues. Such mechanism will help extend the duration of task performance. However, this mechanism may accelerate the development of creep among lumbar passive tissues (Solomonow et al., 2003; Shin \& Mirka, 2007).

Creep deformation causes reduced stiffness among lumbar passive tissues, which compromises the stability of the lumbar structure and its ability to overcome external loading (Adams, Dolan, \& Hutton, 1987; Olson, Li, \& Solomonow, 2004; Solomonow, 2004). In addition, with the presence of significant amount of lumbar passive tissue creep, larger muscle contraction forces may be needed to compensate the reduced internal moment (McCook, Vicenzino, \& Hodges, 2009; Olson, Li, \& Solomonow, 2009), which could lead to muscle fatigue (Shin et al., 2009; Adams \& Dolan, 1995). As a result, the overall spinal stability could be further reduced, therefore elevates the risk of LBP (Solomonow et al., 2000; Granata \& Orishimo, 2001; Cholewicki \& McGill, 1996; Solomonow, 2004). In the past, lumbar passive tissue creep has been observed after maintaining fully flexed trunk posture for a long period of time. McGill and Brown (1992) reported that after $20 \mathrm{~min}$ of static trunk full flexion, lumbar flexion angle increased by an average of $5.5^{\circ}$. Another study observed an average increase in the lumbar flexion angle by $\sim 4^{\circ}$ after performing $10 \mathrm{~min}$ of full trunk flexion (Shin \& Mirka, 2007). Clearly, the development of lumbar passive tissue creep is associated with both the magnitude of load and the duration of loading; previous studies suggested that lumbar passive tissues will collectively carry more than $100 \mathrm{Nm}$ of moment in a fully flexed trunk posture (Ning et al., 2012; Ning \& Nussbaum, 2015). In midrange trunk flexion postures, such as the ones tested in the current study (i.e. $30^{\circ}$ and $60^{\circ}$ of trunk flexion) lumbar passive tissues will experience much lower loadings compare to a fully flexed posture, however, with repetitive and/or prolonged task performance, the development of creep along passive tissues is possible. Such effect therefore warrants future investigation.

Findings of the current study show relatively small differences between outcomes obtained from different conditions. For the $60^{\circ}$ condition, lumbar angle increased significantly in both conditions (i.e. with and without hand load) (Fig. 3) and NEMG activities from L3P and L4P decreased significantly in both conditions as well (Fig. 5). For the $30^{\circ}$ condition, although increase of lumbar angles was observed in both load conditions, such change was only significant when no hand load was introduced (from $-19.29^{\circ}$ to $-18.45^{\circ}$ ); similarly, reductions of L3P and L4P muscle activities were observed in both load conditions, but such reduction in L3P muscle activity was not significant in the no hand load condition.

A possible explanation for the non-significant increase (from $-18.43^{\circ}$ to $-18.00^{\circ}$ ) of lumbar angle for the $30^{\circ}$, with hand load condition is that the lumbar spine was already in a more flexed posture as compared to the without hand load condition. Regarding the significant reduction of NEMG activities in this condition, it is possible that a portion of the load was shifted to deeper or other muscles (e.g. the thoracic section of the Erector Spinae, psoas major, quadratus lumborum, and iliacus) that were not sampled in the current study. 
Results presented in Table 3 also showed larger changes in the lumbar angle, lumbar extensor muscle (i.e. L3P and L4P) activities, and LPM during the course of static trunk bending when more flexed trunk posture was maintained (i.e. $60^{\circ}$ ). It is possible that in more flexed trunk postures, participants experienced larger external loading and lumbar extensor muscles were initially activated at higher levels (Fig. 5), therefore, to avoid the accumulation of muscle fatigue, more loading has to be transferred to lumbar passive tissues. However, it is possible that this statement will not hold true when a deeper trunk flexion posture is tested, because when reaching close to a fully flexed trunk posture, lumbar extensor muscle activities will be significantly reduced (Ning et al., 2011; Sarti et al., 2001), therefore reducing the need of transferring load to lumbar passive tissue.

Results of the present work showed that holding an external load during short duration sustained trunk bending postures did not affect the amount of changes in lumbar posture and LPM significantly (Table 2). A potential explanation could be the relatively light external load used in this study (i.e. $6.8 \mathrm{~kg}$ ) and the short duration of exposure. Heavier hand load and longer posture holding duration could possibly introduce more changes to lumbar biomechanics.

Findings of the present study demonstrated that in real occupational settings, when workers are required to perform static trunk bending (e.g. during harvesting, masonry work or working on assembly lines, etc.), the spinal loading can be gradually shifted from lumbar active tissues to passive tissues over time. A recently published spine model demonstrated that when lumbar spine and trunk flexed beyond a critical point (i.e. active region boundary) the majority of the external loading shifted from active lumbar muscles to passive tissues (Ning, 2017). In such a scenario, lumbar passive tissues serve as the main load bearer in counterbalancing the external moment. However, as discussed earlier, increased loading may lead to the development of creep among lumbar passive tissues. Results of this study suggested that workers that perform static trunk bending tasks will naturally adopt a load shifting strategy to avoid or slow down the accumulation of muscle fatigue.

The current study has several limitations that need to be noted. To avoid the possibility of unwanted lumbar muscle fatigue, relatively short duration of static trunk bending tasks were performed. Future studies should investigate the changes of lumbar postures and trunk muscle activities when performing static trunk bending for longer periods of time. In addition, no significant effect of the hand load was observed, however it could be a result of the relatively light hand load used in this study. Furthermore, the accuracy of the LPM model used in the current study has not been tested on the present population. Finally, only male participants were recruited in the present work. Previous studies reported that females may have slightly different lumbar tissue structure and soft tissue viscoelastic properties (McGill \& Brown, 1992; Norton, Sahrmann, \& Van Dillen, 2004), which warrants further investigation.

\section{Conclusion}

The purpose of the current study was to investigate lumbar biomechanics during short duration static trunk bending tasks. During the performance of these tasks, although the 
general trunk positions (and the associated task requirement) remain unchanged, the underlying mechanism of controlling the equilibrium between external and internal moment was found to undergo several changes. The main finding of the present work is that during the performance of a short duration (i.e. 40 s) static trunk bending participants adopted a motor strategy to shift loading from lumbar active tissues to passive tissues. This mechanism could help prevent or reduce the accumulation of muscle fatigue, however such mechanism may lead to creep development among lumber passive tissues.

\section{References}

Adams M, Dolan P. Recent advances and their clinical in lumbar spinal mechanics significance. Clinical Biomechanics. 1995; 10:3-19. [PubMed: 11415526]

Adams MA, Dolan P, Hutton WC. Diurnal variations in the stresses on the lumbar spine. Spine. 1987; 12(2):130-137. [PubMed: 3589804]

Adams MA, Freeman BJ, Morrison HP, Nelson IW, Dolan D. Mechanical initiation of intervertebral disc degeneration. Spine. 2000; 25(13):1625-1636. [PubMed: 10870137]

Arjmand N, Plamondon A, Shirazi-Adl A, Lariviére C, Parnianpour M. Predictive equations to estimate spinal loads in symmetric lifting tasks. Journal of Biomechanics. 2011; 44(1):84-91. [PubMed: 20850750]

Arjmand N, Shirazi-Adl A. Biomechanics of changes in lumbar posture in static lifting. Spine. 2005; 30(23):2637-2648. [PubMed: 16319750]

Bazrgari B, Shirazi-Adl A. Spinal stability and role of passive stiffness in dynamic squat and stoop lifts. Computer Methods in Biomechanics and Biomedical Engineering. 2007; 10(5):351-360. [PubMed: 17852177]

Bernard, BP. Musculoskeletal disorders and workplace factors: A critical review of epidemiologic evidence for work-related musculoskeletal disorders of the neck, upper extremity, and low back. US Department of Health and Human Services (DHHS) publ; Cincinnati: National Institute for Occupational Safety and Health); 1997. US Department of Health and Human Services (DHHS) publication no. 97-141

Boschman JS, van der Molen HF, Sluiter JK, Frings-Dresen MH. Occupational demands and health effects for bricklayers and construction supervisors: A systematic review. American Journal of Industrial Medicine. 2011; 54(1):55-77. [PubMed: 20886532]

Brinckmann P, Biggemann M, Hilweg D. Fatigue fracture of human lumbar vertebrae. Clinical Biomechanics. 1988; 3 S1-ii-S23.

Cholewicki J, McGill SM. Mechanical stability on the in vivo lumbar spine: Implications for injury and chronic low back pain. Clinical Biomechanics. 1996; 11(1):1-15. [PubMed: 11415593]

Coenen P, Kingma I, Boot CR, Bongers PM, van Dieën JH. The contribution of load magnitude and number of load cycles to cumulative low-back load estimations: A study based on in-vitro compression data. Clinical Biomechanics. 2012; 27(10):1083-1086. [PubMed: 22877832]

Coenen P, Kingma I, Boot CR, Twisk JW, Bongers PM, van Dieën JH. Cumulative low back load at work as a risk factor of low back pain: A prospective cohort study. Journal of Occupational Rehabilitation. 2013; 23(1):11-18. [PubMed: 22718286]

De Luca CJ. The use of surface electromyography in biomechanics. Journal of Applied Biomechanics. 1997; 13:135-163.

Descarreaux M, Lafond D, Jeffrey-Gauthier R, Centomo H, Cantin V. Changes in the flexion relaxation response induced by lumbar muscle fatigue. BMC Musculoskeletal Disorders. 2008; 9(1):10. [PubMed: 18218087]

Deyo RA, Mirza SK, Martin BI. Back pain prevalence and visit Rates: Estimates from U.S. National Surveys, 2002. Spine. 2006; 31(23):2724-2727. [PubMed: 17077742]

Fathallah FA. Musculoskeletal disorders in labor-intensive agriculture. Applied Ergonomics. 2010; 41(6):738-743. [PubMed: 20398891] 
Floyd WF, Silver PHS. Function of erectores spinae in flexion of the trunk. The Lancet. 1951; 260:133-134.

Floyd WF, Silver PHS. The function of the erectores spinae muscles in certain movements and postures in man. The Journal of Physiology. 1955; 129(1):184-203. [PubMed: 13252593]

Gallagher, S. Reducing low back pain and disability in mining. Department of Health and Human Services, Centers for Disease Control and Prevention, National Institute for Occupational Safety and Health (NIOSH), Pittsburgh Research Laboratory; 2008.

Gatchel RJ, Polatin PB, Mayer TG. The dominant role of psychosocial factors in the development of chronic low back pain disability. Spine. 1995; 20(24):2702-2709. [PubMed: 8747248]

Granata KP, Orishimo KF. Response of trunk muscle coactivation to changes in spinal stability. Journal of Biomechanics. 2001; 34(9):1117-1123. [PubMed: 11506782]

Hellmann, DB., Imboden, JB, Jr. Musculoskeletal and immunologic disorders. 48. McPhee, SJ., Papadakis, MA., editors. New York: McGraw-Hill Companies Inc; 2009.

Hoogendoorn WE, Bongers P, Henrica CW, Douwes M, Koes BW, Miedema MC, et al. Flexion and rotation of the trunk and lifting at work are risk factors for low back pain. Spine. 2000; 25:30873092. [PubMed: 11145822]

$\mathrm{Hu} \mathrm{B}$, Ning X. The changes of trunk motion rhythm and spinal loading during trunk flexion and extension motions caused by lumbar muscle fatigue. Annals of Biomedical Engineering. 2015a; 43(9):2112-2119. [PubMed: 25589373]

$\mathrm{Hu} \mathrm{B}$, Ning X. The influence of lumbar extensor muscle fatigue on lumbar-pelvic coordination during weightlifting. Ergonomics. 2015b; 58(8):1424-1432. [PubMed: 25677418]

Junqueira DRG, Ferreira ML, Refshauge K, Maher CG, Hopper JL, Hancock M, et al. Heritability and lifestyle factors in chronic low back pain: Results of the Australian Twin Low Back Pain Study (The AUTBACK study). European Journal of Pain. 2014; 18(10):1410-1418. [PubMed: 24733726]

Kahrizi S, Parnianpour M, Firoozabadi S. Evaluation of spinal internal loads and lumbar curvature under holding static load at different trunk and knee positions. Pakistan Journal of Biological Sciences. 2007; 10(7):1036-1043. [PubMed: 19070047]

Katz JN. Lumbar disc disorders and low-back pain: Socioeconomic factors and consequences. The Journal of Bone \& Joint Surgery. 2006; 88(Suppl 2):21-24. [PubMed: 16595438]

Luo X, Pietrobon R, Sun SX, Liu GG, Hey L. Estimates and patterns of direct health care expenditures among individuals with back pain in the United States. Spine. 2004; 29(1):79-86. [PubMed: 14699281]

Marras WS, Davis KG, Ferguson SA, Lucas BR, Gupta P. Spine loading characteristics of patients with low back pain compared with asymptomatic individuals. Spine. 2001; 26(23):2566-2574. [PubMed: 11725237]

Marras WS, Ferguson SA, Kim JY, Crowell RR, Bose S, Simon SR. The classification of anatomicand symptom-based low back disorders using motion measure models. Spine. 1995; 20(23):25312546. [PubMed: 8610248]

Marras WS, Granata KP. The development of an EMG-assisted model to assess spine loading during whole-body free-dynamic lifting. Journal of Electromyography and Kinesiology. 1997; 7(4):259268. [PubMed: 11369269]

McCook DT, Vicenzino B, Hodges PW. Activity of deep abdominal muscles increases during submaximal flexion and extension efforts but antagonist co-contraction remains unchanged. Journal of Electromyography and Kinesiology. 2009; 19(5):754-762. [PubMed: 18160311]

McGill SM. Biomechanics of low back injury: Implicationa for the workplace and clinic. Journal of Biomechanics. 1997; 30(5):465-475. [PubMed: 9109558]

McGill SM, Brown S. Creep response of the lumbar spine to prolonged full flexion. Clinical Biomechanics. 1992; 7(1):43-46. [PubMed: 23915616]

McGill SM, Hughson RL, Parks K. Changes in lumbar lordosis modify the role of the extensor muscles. Clinical Biomechanics. 2000; 15(10):777-780. [PubMed: 11050362]

Mirka GA, Baker A, Harrison A, Kelaher D. The interaction between load and coupling during dynamic manual materials handling tasks. Occupational Ergonomics. 1998; 1(1):3-11. 
Murray CJ, Vos T, Lozano R, Naghavi M, Flaxman AD, Michaud C, ... Aboyans V. Disabilityadjusted life years (DALYs) for 291 diseases and injuries in 21 regions, 1990-2010: a systematic analysis for the Global Burden of Disease Study 2010. The lancet. 2012; 380(9859):2197-2223.

Ning X. An EMG-assisted modeling approach to assess passive lumbar tissue loading in vivo during trunk bending. Journal of Electromyography and Kinesiology. 2017; 36:1-7. [PubMed: 28633066]

Ning X, Haddad O, Jin S, Mirka GA. Influence of asymmetry on the flexion relaxation response of the low back musculature. Clinical Biomechanics. 2011; 26(1):35-39. [PubMed: 20943296]

Ning X, Jin S, Mirka GA. Describing the active region boundary of EMG-assisted biomechanical models of the low back. Clinical Biomechanics. 2012; 27(5):422-427. [PubMed: 22169592]

Ning X, Nussbaum MA. Passive lumbar tissue loading during trunk bending at three speeds: An in vivo study. Clinical Biomechanics. 2015; 30(7):726-731. [PubMed: 25979223]

Norman R, Wells R, Neumann P, Frank J, Shannon H, Kerr M, et al. A comparison of peak vs cumulative physical work exposure risk factors for the reporting of low back pain in the automotive industry. Clinical Biomechanics. 1998; 8(13):561-573.

Norton BJ, Sahrmann SA, Van Dillen LR. Differences in measurements of lumbar curvature related to gender and low back pain. Journal of Orthopaedic and Sports Physical Therapy. 2004; 34(9):524534. [PubMed: 15493520]

Olson MW, Li L, Solomonow M. Flexion-relaxation response to cyclic lumbar flexion. Clinical Biomechanics. 2004; 19(8):769-776. [PubMed: 15342148]

Olson MW, Li L, Solomonow M. Interaction of viscoelastic tissue compliance with lumbar muscles during passive cyclic flexion-extension. Journal of Electromyography and Kinesiology. 2009; 19(1):30-38. [PubMed: 17703955]

Potvin JR, McGill SM, Norman RW. Trunk muscle and lumbar ligament contributions to dynamic lifts with varying degrees of trunk flexion. Spine. 1991; 16(9):1099-1107. [PubMed: 1948399]

Richard AD, Edward B. Lifestyle and low-back pain, the influence of smoking and obesity. Spine. 1989; 14:501-506. [PubMed: 2524888]

Sarti MA, Lison JF, Monfort M, Fuster MA. Response of the flexion-relaxation phenomenon relative to the lumbar motion to load and speed. Spine. 2001; 26(18):E421-E426. [PubMed: 11547213]

Shin G, D'Souza C, Liu YH. Creep and fatigue development in the low back in static flexion. Spine. 2009; 34(17):1873-1878. [PubMed: 19644340]

Shin G, Mirka GA. An in vivo assessment of the low back response to prolonged flexion: Interplay between active and passive tissues. Clinical Biomechanics. 2007; 22(9):965-971. [PubMed: 17709161]

Solomonow M. Ligaments: A source of work-related musculoskeletal disorders. Journal of EMG \& Kinesiology. 2004; 14(1):49-60.

Solomonow M, Baratta RV, Banks A, Freudenberger C, Zhou BH. Flexion-relaxation response to static lumbar flexion in males and females. Clinical Biomechanics. 2003; 18(4):273-279. [PubMed: 12689776]

Solomonow M, Zhou BH, Baratta RV, Lu Y, Zhu M, Harris M. Biexponential recovery model of lumbar viscoelastic laxity and reflexive muscular activity after prolonged cyclic loading. Clinical Biomechanics. 2000; 15(3):167-175. [PubMed: 10656978]

Toosizadeh N, Nussbaum MA, Bazrgari B, Madigan ML. Load-relaxation properties of the human trunk in response to prolonged flexion: Measuring and modeling the effect of flexion angle. PLoS ONE. 2012; 7(11):e48625. [PubMed: 23144913]

Weiner SS, Nordin M. Prevention and management of chronic back pain. Best Practice \& Research Clinical Rheumatology. 2010; 24(2):267-279. [PubMed: 20227647] 


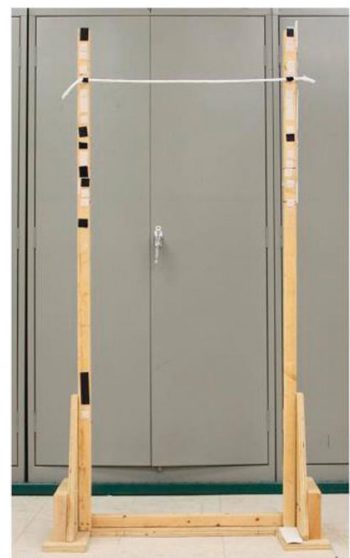

A
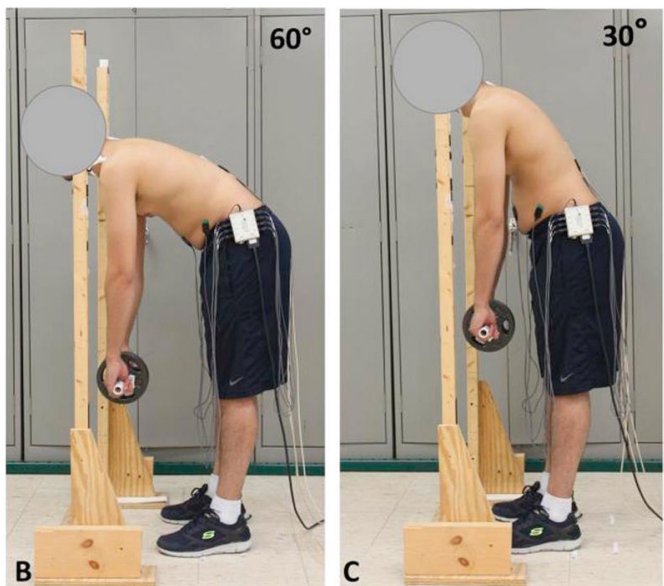

Fig. 1.

The trunk angle reference apparatus (panel A) and experimental setup with the $60^{\circ}$ and $30^{\circ}$ trunk angles (panels B and C respectively). 


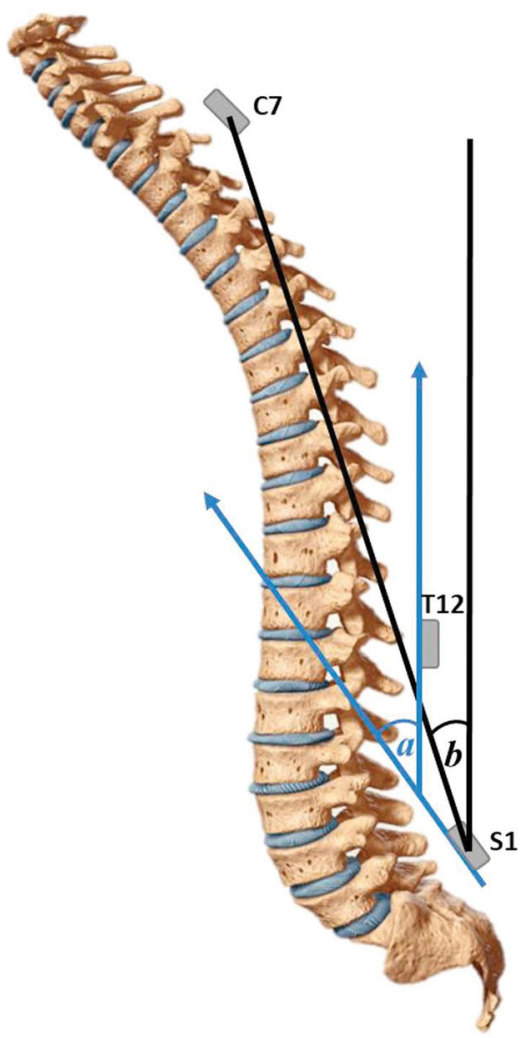

Fig. 2.

A demonstration of the definitions of the lumbar flexion angle "a" and the trunk inclination angle "b". 


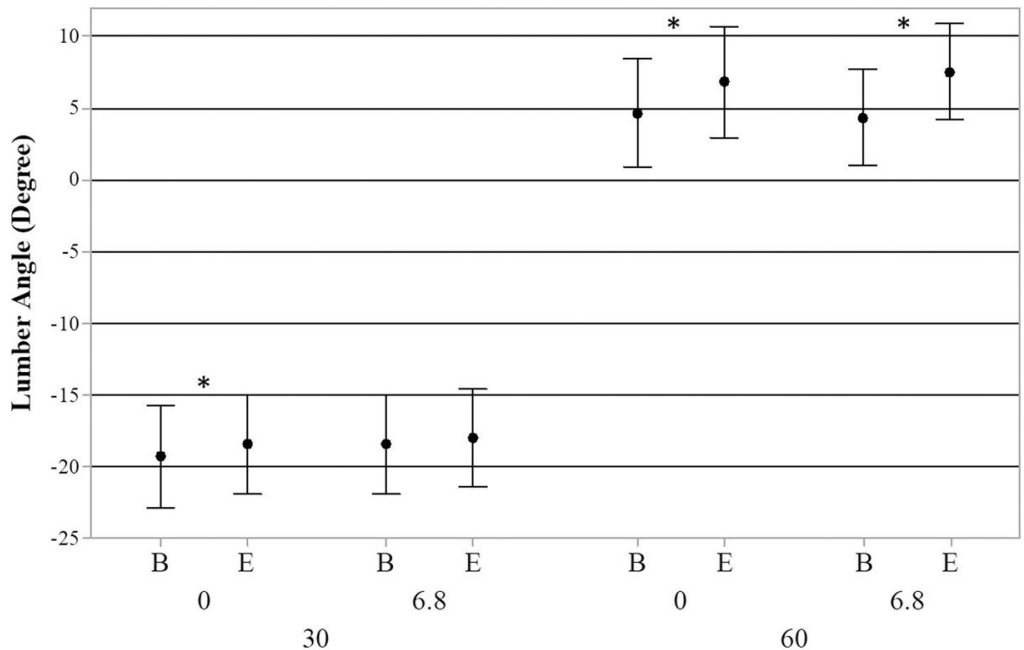

Fig. 3.

Lumbar flexion angle (LA) at the beginning (B) and ending (E) $5 \mathrm{~s}$ of the $40 \mathrm{~s}$ maintained posture at different conditions of TA (i.e. $30^{\circ}$ and $60^{\circ}$ ) and LOAD (i.e. 0 and $6.8 \mathrm{~kg}$ ). Star indicates significant change. Bars indicate the corresponding standard deviations. 


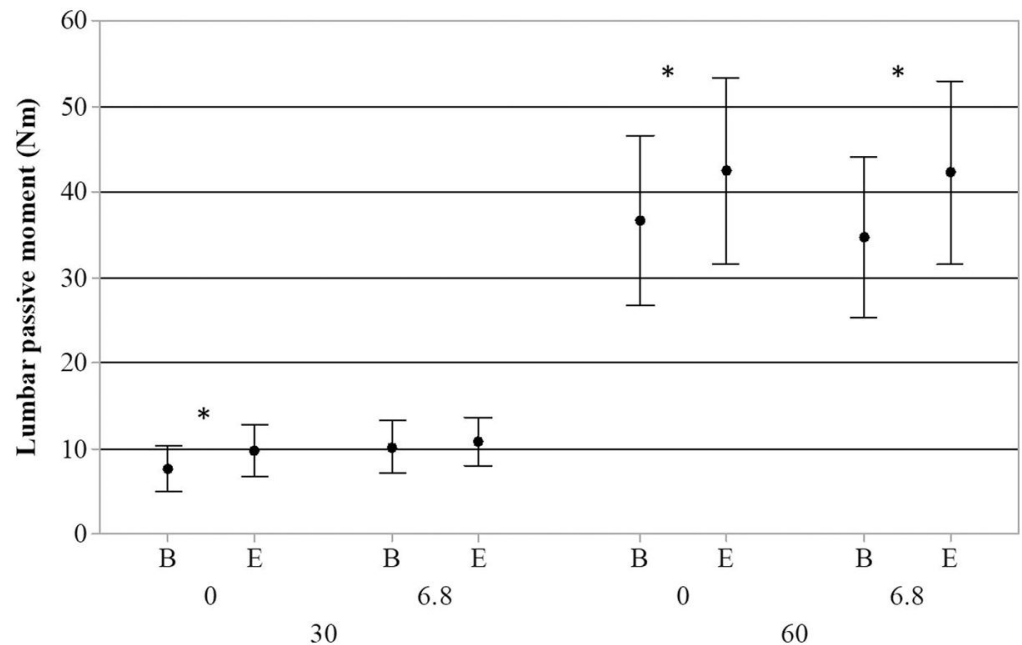

Fig. 4.

Lumbar passive moment (LPM) at the beginning (B) and ending (E) $5 \mathrm{~s}$ of the $40 \mathrm{~s}$ maintained posture at different conditions of TA (i.e. $30^{\circ}$ and $60^{\circ}$ ) and LOAD (i.e. 0 and 6.8 $\mathrm{kg})$. Star indicates significant change. Bars indicate the corresponding standard deviations. 


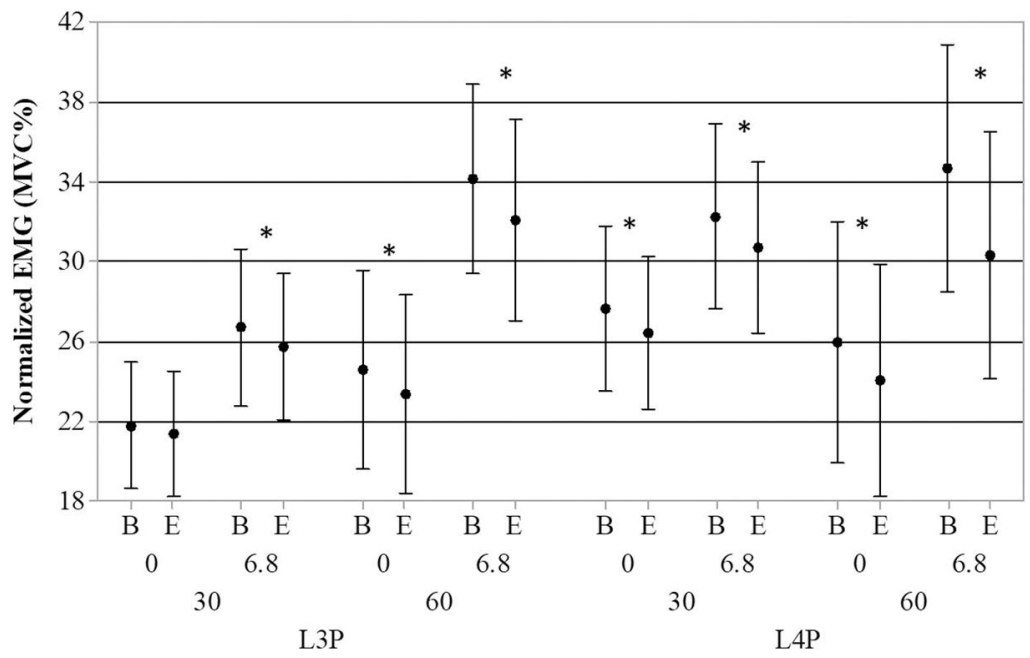

Fig. 5.

Normalized EMG signals for L3P and L4P at the beginning (B) and ending (E) $5 \mathrm{~s}$ of the 40 s maintained posture at different conditions of TA (i.e. $30^{\circ}$ and $60^{\circ}$ ) and LOAD (i.e. 0 and $6.8 \mathrm{~kg}$ ). Star indicates significant change. Bars indicate the corresponding standard deviations. 


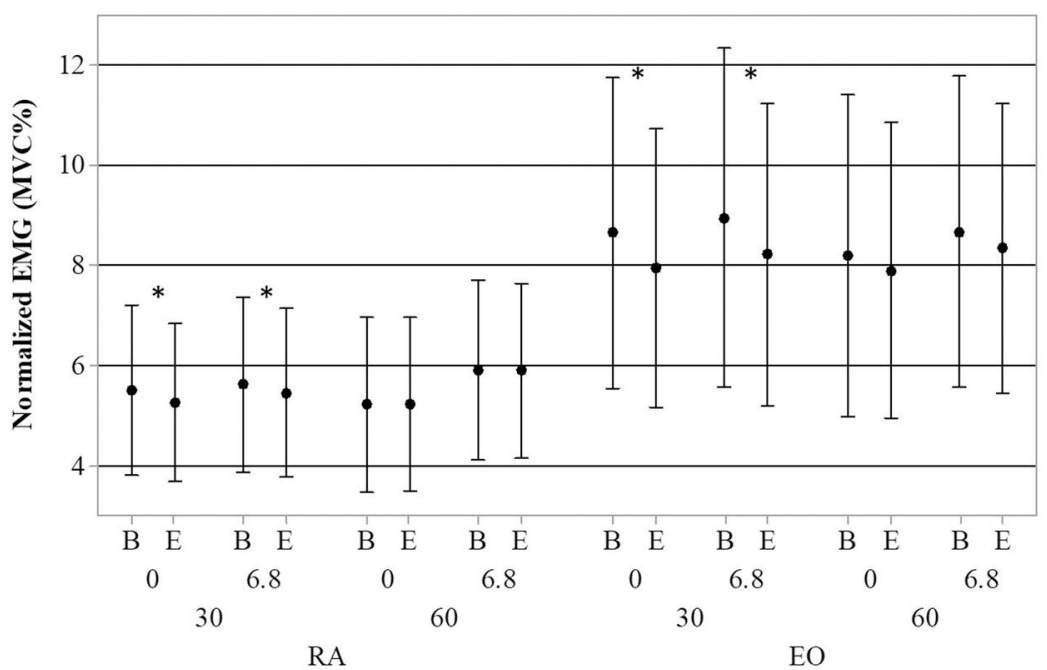

Fig. 6.

Normalized EMG signals for RA and EO at the beginning (B) and ending (E) $5 \mathrm{~s}$ of the $40 \mathrm{~s}$ maintained posture at different conditions of TA (i.e. $30^{\circ}$ and $60^{\circ}$ ) and LOAD (i.e. 0 and 6.8). Star indicates significant change. Bars indicate the corresponding standard deviations. 


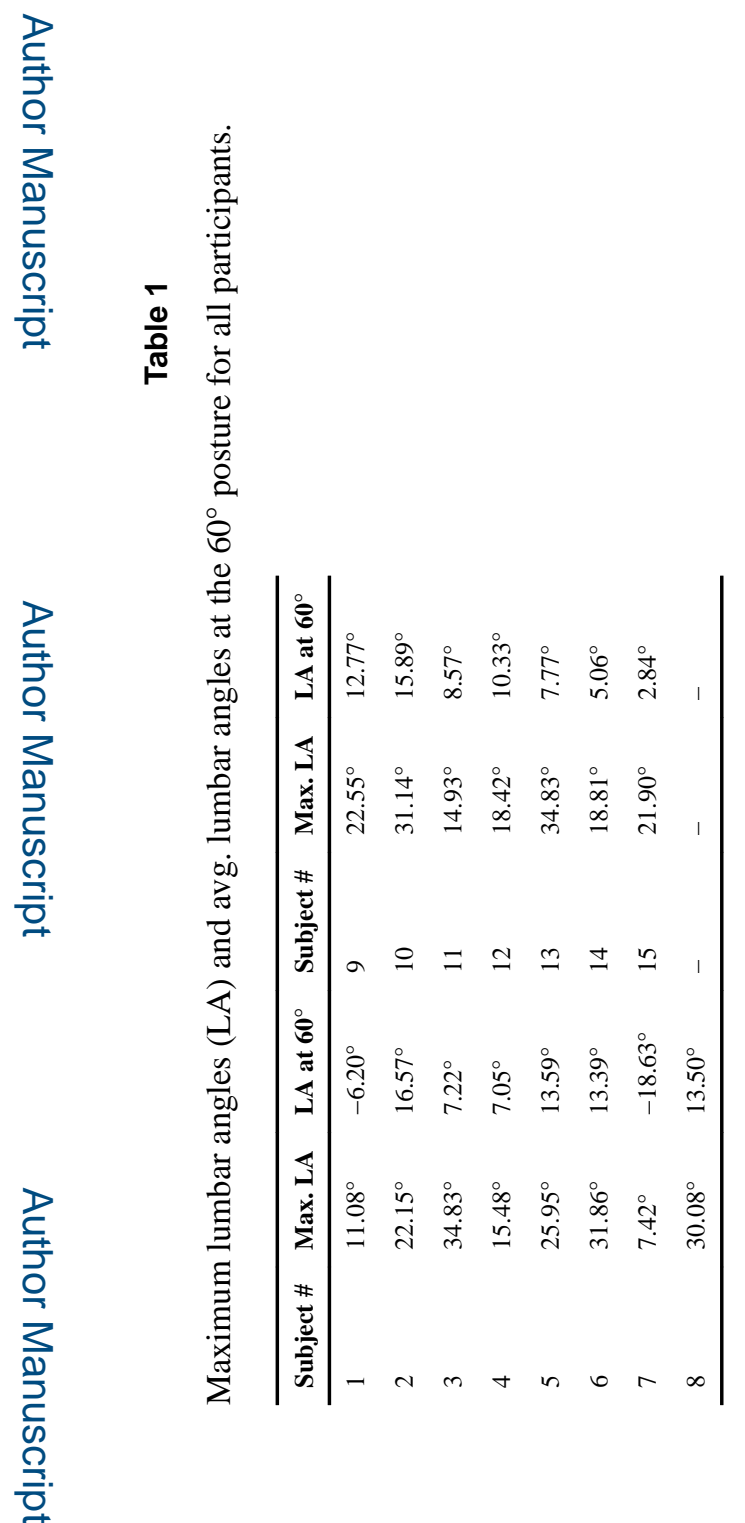

Hum Mov Sci. Author manuscript; available in PMC 2019 February 01. 


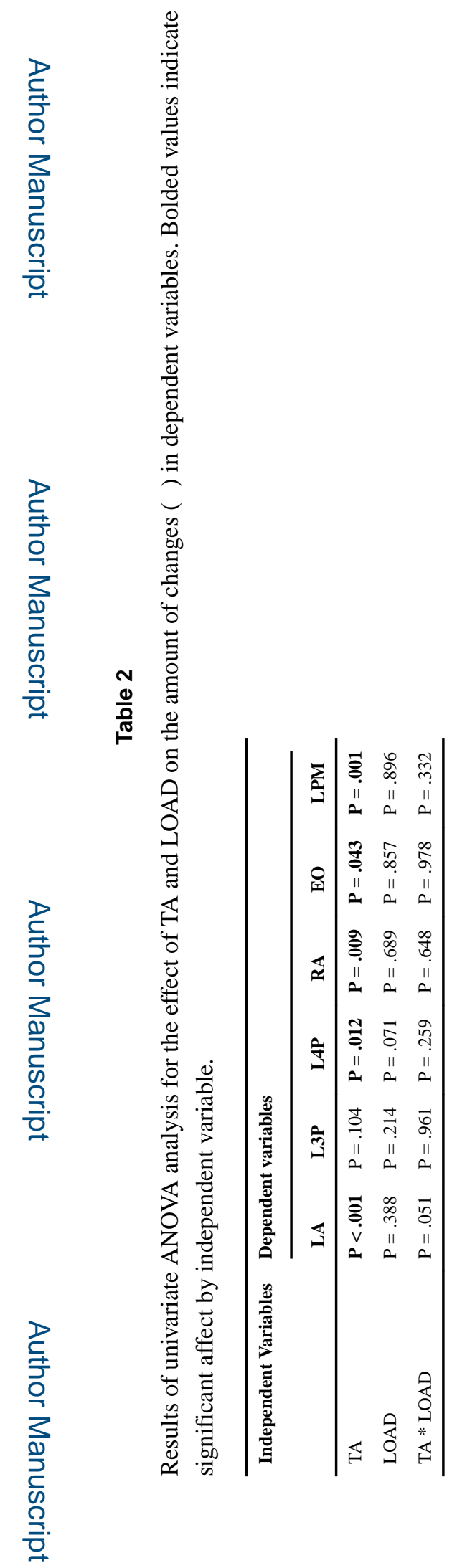

Hum Mov Sci. Author manuscript; available in PMC 2019 February 01. 


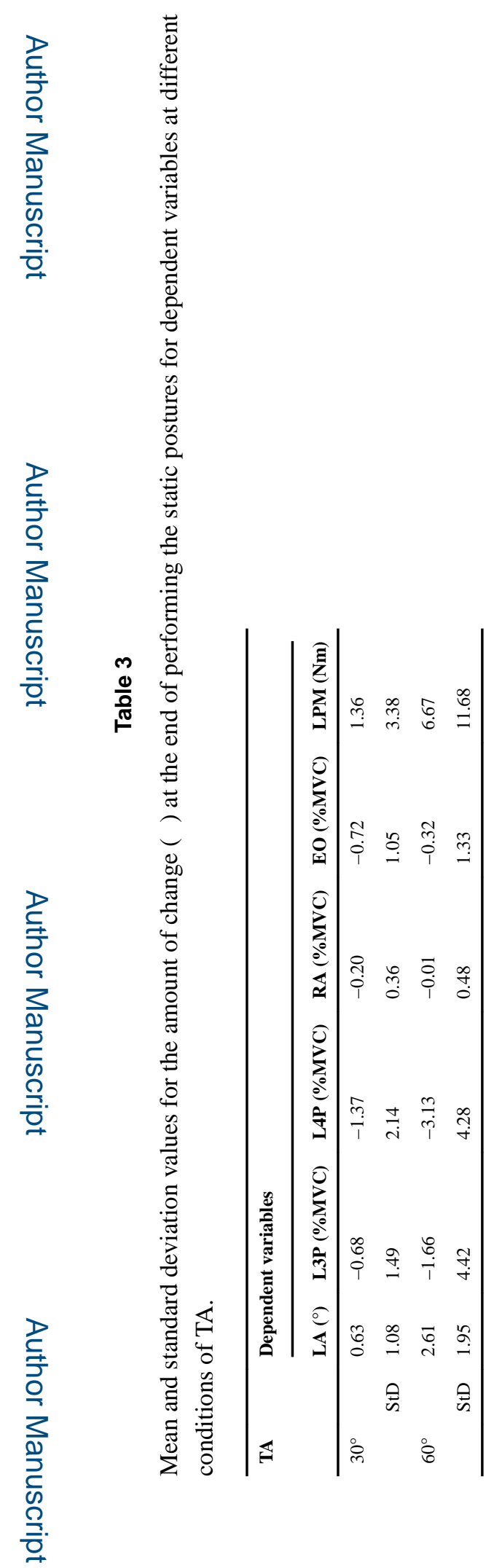

Hum Mov Sci. Author manuscript; available in PMC 2019 February 01. 